\title{
Just Art for a Just City: Public Art and Social Inclusion in Urban Regeneration
}

\author{
Joanne Sharp, Venda Pollock and Ronan Paddison
}

[Paper first received, September 2004; in final form, January 2005]

Summary. In this article, it is shown how cultural policy, and in particular public art, intersects with the processes of urban restructuring and how it is a contributor, but also antidote, to the conflict that typically surrounds the restructuring of urban space. The particular focus of the paper is on investigating how public art can be inclusionary/exclusionary as part of the wider project of urban regeneration. The first part of the paper examines examples in which public art intervention has attempted to generate inclusion. Subsequently, attention focuses more on examples in which the public art has been perceived as an aspect of cultural domination and has thus provoked resistance. Throughout, it is argued that the processes through which artworks become installed into the urban fabric are critical to the successful development of inclusion.

\section{Introduction}

As part of the celebration of Scottish devolution, implemented in 1999, but also as a sculpture intended to be a part of the restructuring of the 'new Glasgow', a statue to Donald Dewar was erected at a prominent location in the city centre. Generally acclaimed as the 'father' of Scottish devolution, but also an MP of long standing in the city, a statue to him seemed a fitting celebration of his achievements. Moreover, its emplacement at the head of a newly pedestrianised area and immediately outside the new Concert Hall, itself a product of the city's status as European City of Culture in 1990, seemed an appropriate gesture to both the city and Scotland. Yet, repeatedly, the statue has been vandalised, to the point that the city council considered relocating it, or at least, through raising the height of the plinth on which it stands, making its vandalism more difficult.
As it is, the statue remains at its original site, although as a result of vandalism the subject often lacks his spectacles and is periodically embellished with graffiti.

The story the Donald Dewar statue tells is one repeated elsewhere, that public art can be read in different ways and that its uses to beautify the city or celebrate its reimagineering do not necessarily enjoy universal consensus. In this respect, public art is no different from art in general where matters of taste and preference become paramount. For public art, these issues become magnified precisely because of its visibility and hence its 'inescapability', although reactions to it can vary from the highly vocal and oppositional to the unaffected. Time can help to mellow public opinion to artworks so they become part of not just the taken-for-granted but also of the accepted landscape of the city. A few years before the unveiling of the statue to 
Donald Dewar, public opposition had been vocal to the suggestion made by Glasgow City Council to relocate statues from the city's principal square. Yet, ironically, the statues commemorate largely forgotten political and military figures of the 19th century and are symptomatic of the 'imposed monumentalism' of the Victorian city. What Lefebvre (1991, p. 143) warned of as the ability of "monumental buildings to mask the will to power and the arbitrariness of power beneath signs and surfaces which claim to express collective will and collective thought", is given added weight through the impress of time and habituation.

Such contradictions underline the different readings public art attracts, but they also suggest how its meaning, for the self and more specifically the self as citizen, can be read as more or less inclusive. Where exclusion reflects authoritarian imposition, it is in the colonial city that the alienating effects generated by public art, particularly that celebrating imperial control, foster political reaction and the will to decommemorate alien rule. Thus, following Irish independence, the monumental symbols to British rule in Dublin were successively removed, sometimes by the state at others clandestinely by nationalist groups. Yet as Whelan (2003) shows in the case of the most obvious of the icons, certainly the most prominent in the urban landscape-Nelson's Pillar modelled on its London counterpart-opinions as to its fate were divided. Ultimately it was to be decided by the bomb. Yet in spite of the overt political symbolism of the pillar, its familiarity and acceptance as part of the everyday use of the city, as well as appreciation of its aesthetic qualities, meant that its removal was not uncontentious. As Whelan has argued

With the passage of time it became a popular meeting-place and viewing point ... and a symbol of the city centre that transcended any political connotations (Whelan, 2003, p. 206, emphasis added).

Such decommemoration is commonplace in cities emergent from periods of authoritarian rule-although not necessarily uncontested as can be the remonumentalisation of (urban) space (Czaplicka and Ruble, 2003).

Where the development of public art as part of the repertoire of the gentrification of the contemporary city lacks the overt political symbolism of monumentalism (Levinson, 1998), this is not to suggest that its use is politically neutral. Deutsche (1996) argues forcefully how the promotion of public art and architecture appears to neutralise politically its use within the city yet masks its political outcomes, particularly on those excluded from the new image created. Contemporary trends in public art in the city have tended to eschew monumentalism as it was expressed in the 19th century with its thinly disguised appeal to élite interests. Further, much as public art and architecture in Rome or Florence in the Reformation had been fashioned to celebrate the city and in the 19th century became part of the process of forging the City Beautiful, so its present use, in part at least, can be seen as part of the ongoing goal of beautifying the city. Yet the (re)aestheticisation of cities is not an apolitical exercise; the Hausmannisation of European cities in the 19th century and its 'imposed' nature and socially divisive outcomes have their parallels in the contemporary restructuring of the city under what Harvey (2000) has described as 'neoliberalised urban authoritarianism'. Much as historical analogy risks glossing over contextual differences, what Gunn (2000) has sought to demonstrate as the dominance of bourgeois values on the landscapes of the cities of northern England in the 19th century has come to be repeated albeit in a different guise in the bourgeois revanchism underpinning contemporary urban gentrification (Smith, 1996).

What the experience of urban regeneration continues to repeat is that the uses to which culture has been employed as part of the process of revival can be socially divisive leading to what Mitchell (2000) has described as 'culture wars'. As has been widely remarked upon (for example, see Bianchini, 1999; Boyle and Hughes, 1991), cultural planning immediately raises the question of 'culture for whom?' in which imposition and 
the favouring of particular interests are likely to engender reaction and resistance. To its practitioners, there may be a degree of inevitability here, particularly where the reimagineering of cities has become so focused around the winning of mega-events; the focused nature of such events may be incompatible with the ability to address the diverse set of preferences represented in the city. Yet where 'culture wars' arise, their development reflects the wider problem (and challenge) apparent in contemporary urban restructuring in which the battleground of city politics comprises two 'sides' of urban entrepreneurialism caught up in the avowed objective of making the city more competitive and the increasing social inequalities that have become so much the hallmark of such cities.

In this article, we want to show how cultural policy, and in particular public art, intersects with the processes of urban restructuring and how it is a contributor, but also antidote, to the conflict that typically surrounds the restructuring of urban space. Even restricting our attention to the field of public art, it is apparent that these intersections are complex and contextually dependent. Our intention is to 'cut into' the picture through asking two sets of questions linked to the overarching purpose of investigating how public art can be inclusionary/exclusionary in the methods through which it has been practised as part of the wider project of urban regeneration.

- In the deployment of public art, what conditions contribute to or hinder democratically inclusive practices? How is local participation able to counter top-down practices? How do design professionals, architects and artists, seek to develop inclusive practices? Is inclusion seen as an end in itself or a means to an end, and by whom?

- In what ways have the claims made for the use of public art within urban regeneration been inclusive? Under what conditions does inclusion contribute to a sense of democratic ownership over the inscription of urban spaces? How does this vary between different types of public art and architecture, and in different types of urban space?

Fundamentally, our concern in this paper is to offer critical insight into how public art and architecture contribute or otherwise to the social cohesion of the city. Key to the creation of social cohesion is the belief that public art, or the processes through which it is produced, is able to create a sense of inclusion. By this token, public art should be able to generate a sense of ownership forging the connection between citizens, city spaces and their meaning as places through which subjectivity is constructed. Initially, we outline the rationale for identifying public art and the critiques that are used to counter the rhetoric underpinning its adoption. Here, we are concentrating on the visual so excluding those other elements of the arts, notably the performative, that other writers have sought to include within its definition (Deutsche, 1996; Lippard, 1997; Miles, 1997). The main discussion is divided into two sections looking at different types of in(ex)clusive practice through different case studies. Initially, we look at examples in which public art intervention has been sought inclusively. Subsequently, attention focuses more on examples in which cultural domination has provoked resistance. Throughout, it is argued that in the deployment of public art it is the processes through which it becomes installed into the urban fabric that are critical to inclusion. However, practice also emphasises differences between the motivations underpinning the use of public art, the scale of intervention and the perceived importance of it to the reaestheticisation of urban spaces.

\section{Why Public Art?}

Public art is not simply art placed outside. Many would argue that traditional gallery spaces are public in their openness to interested viewers, while, conversely, others would insist that the privatisation of public space has meant that art placed in public space is not necessarily for all. Thus, public art is art which has as its goal a desire to engage with 
its audiences and to create spaces-whether material, virtual or imagined-within which people can identify themselves, perhaps by creating a renewed reflection on community, on the uses of public spaces or on our behaviour within them. Public art, then, does not have only to be expressed visually. It can be expressed in terms of soundscapes, media (non-)places such as the Internet, on television, as well as in material spaces of inhabited landscapes. However, given the focus here on the links between arts and urban regeneration, we have chosen to concentrate on the visual. The core examples relate to the urban environment, yet consideration is also made of some that may lie somewhat outwith the urban realm but are integrally related to ideas of ownership, identity and the creation of space.

In the UK, as in many other contemporary Western countries, public art appears to have an increasingly prominent role in urban design. In 1993, around 40 per cent of local authorities in the UK had adopted a public art policy of some sorts (Miles, 1997, p. 96) and since then progressively more cities, like Newcastle and Gateshead, have been using public art as a keystone in their regeneration schemes. Hall and Robertson (2001, p. 7) cite the general aim of adding an " "aura' of quality", listing the Policy Studies Institute's summary of the contribution that public art can make to a number of contemporary urban issues: contributing to local distinctiveness; attracting investment; boosting cultural tourism; enhancing land values; creating employment; increasing use of urban spaces; and, reducing vandalism. For its advocates, there is an overall sense of the significant role that public art can play in culture-led urban regeneration, in the economic realm, but also in terms of culture and community.

It is perhaps the perceived potential of public art to work on multiple levels and its adaptability that gives it such cultural viability. Public art not only contributes to the visual attractiveness of the city and has the ability to aestheticise urban spaces, but also, through public art, authorities can signal their willingness to deal with social and environmental problems. For many authorities, inclusive, community-based projects appeal because they are generally lowcost and yet are perceived to be able to yield benefits beyond the aesthetic that correlate with social policy objectives. However, the way in which such projects are inscribed into regeneration policy has implications, as Phillips (1988) suggests, for the potential of the artwork. The arts represent

the more intangible phenomenon whereby cultural resources are mobilised by urban managers in an attempt to engineer consensus amongst the residents of their localities, a sense that beyond the daily difficulties of urban life which many of them might experience the city is basically doing 'alright' by its citizens (Philo and Kearns, 1993, p. ix).

Phillips (1988) and Deutsche (1996) have been quick to point out that the notion of the public should not be regarded as a neat, always consensual affair. Many arguments are based on essentialist claims to nature, identity, place and community. They thus fail to acknowledge the contested, fragmented and mutable nature of these concepts. Deutsche (1996, p. 270) worries that those who see public art as leading to the enhancement of community miss the point in that they "presume that the task of democracy is to settle, rather than sustain, conflict". Public space and the controversies surrounding public art can only reflect their constituent communities. Hall and Robertson (2001, p. 19) argue that the role of public art should be to encourage the sound of contradictory voices-voices that represent the diversity of people using the space-rather than aspire "to myths of harmony based around essentialist concepts". Phillips further points to the bureaucracy that so much public art now has to negotiate given the intended goals of inclusion-from the different committees that must examine and accept proposals to considerations of health and safety-that any critical edge is lost and the resultant work must be bland, engaging everyone but offending no-one. She says 
Isn't it ironic that an enterprise aimed even at the least, at enlivening public life is now running on gears designed to evade controversy (Phillips, 1988, p. 95).

\section{Approaching Inclusion}

One of the more pressing issues characterising contemporary cities-certainly one which preoccupies much academic and policy debate-is how to achieve greater social inclusion in cities which, locked into the task of enhancing their competitive position in an increasingly globalised economy, are characterised by deepening socioeconomic inequalities and increasing segregation. The apparent unambiguity of the issue belies the complications to which it gives rise. How is inclusion to be defined? How is it to be sought? What are the presumed linkages between social inclusion and urban economic competitiveness? Such fundamental issues problematise not only how inclusion should be formulated within urban policy but also its purpose and benefits-questions that recur within the use of public art as part of the process of regenerating the city and its neighbourhoods.

As it has been suggested, even the linkages between social inclusion and urban economic competitiveness are disputed. To some (for example, Marcuse and van Kempen, 2002), social inclusion, or rather its antonym social exclusion, erodes the ability of the city to be competitive. Cities characterised by deep socioeconomic inequalities would be less attractive to investment capital undermining their ability to maintain their competitiveness. Further, as an argument to which New Labour's urban policy has given explicit support (Imrie and Raco, 2003), social inclusion was not only important to the attainment of economic competitiveness but through the Third Way the achievement of both was possible (Giddens, 1998). Not only would the opportunities to participate be enhanced in a prosperous (urban) economy, but also the benefits of growth would trickle down the social hierarchy. Inclusion, then, becomes a necessary part of a virtuous cycle of urban growth, an argument which was to be tested in different ways in the recent research project Cities: Competitiveness and Cohesion Research Programme funded by the Economic and Social Research Council in the UK. The evidence of the programme was far from supportive of the linkage. Indeed, as the authors to the report summarising the programme suggested, from the evidence of Britain's 'successful cities', such as London, Leeds, Bristol or Edinburgh,

it is clear that competitive success is far from incompatible with persistent concentrations of unemployment and social deprivation and high levels of social and economic inequality (Boddy and Parkinson, 2004, p. 428).

What the research identified was what has been empirically demonstrated elsewhere, that urban economic restructuring is often accompanied by deepening socioeconomic inequalities (Sassen, 2001; Madanipour et al., 1998). Even if, as Moulaert et al. (2003) suggest, the impress of such inequalities varies according to the type of welfare regime and the regulatory frameworks through which urban policy is mediated, such differences do not negate the uncertainty surrounding the linkages between social inclusion and economic change.

These uncertainties become replicated in debates on the role of public art in urban regeneration. Indeed in the case of public art, doubts surround not only the contribution it might make to urban economic growth, but also to that of social inclusion. Two interrelated factors help to explain the problems: first, the contribution of public art is often deliberately symbolic; and, secondly, following from this, there are methodological problems in evaluating its impacts. Typically, the outcomes of social inclusion as part of urban policy become expressed in material terms. Most urban policy is aimed at reducing material inequalities-for example, through neighbourhood regeneration, the rehabilitation of sub-standard housing stock, training programmes aimed at reinserting the unemployed within the labour market and through 
the quest to improve the delivery of public services in disadvantaged neighbourhoods. As the consequences of public art are perceived to be symbolic rather than material, this tends to increase the conflict surrounding its use, which in turn is amplified by the difficulties in measuring the benefits which are claimed for it (Selwood, 1995). There are exceptions, notably what Plaza (2000) terms the 'Guggenheim effect': the contribution of iconic architecture to the generating of urban tourism and more generally to the regeneration of the city. Most public art, however, is more modest in its intervention and scale and its economic contribution is often marginal and typically indirect. The indeterminacy of its economic contribution places added attention on its imputed non-material benefits. The intangibility and contested nature of these benefits, how they contribute to building social inclusion, shifts the emphasis from outcomes towards the processes through which public art is produced and how these can foster a sense of inclusion. In other words, it is by focusing attention on the democratic processes through which public art is produced and the extent to which these are inclusive that we can begin to appreciate the role of public art in urban regeneration.

Recent debates amongst post-modern political philosophers provide pointers to how democratic processes can (and should) be more inclusive. Young (2000) provides a succinct definition of inclusion as

a democratic decision (being) normatively legitimate only if all those affected by it are included in the process of discussion and decision-making (Young, 2000, p. 22).

Her emphasis is on the processes through which collective decisions are made. Critical here is that the processes in which discussion and deliberation amongst the multiple groups and communities comprising the city afford equal status to each and that debate becomes the means of exposing and being more responsive to difference. Others, notably Fraser (1995, 1997) but also Phillips (2004), have taken issue with the emphasis given by
Young to the politics of difference and the extent to which the overaccentuation of what Fraser defines as cultural injustice has diverted attention from socioeconomic redistribution. As important as such debates are (and they become mirrored elsewhere within the use of culture as a means of urban regeneration), they should not be allowed to overshadow the common ground that exists-the commitment to social justice and the contribution to its attainment through the need for mutual recognition between groups with different preferences, the acceptance of difference and the role deliberative processes of political interaction can play.

Fraser (1995, p. 71) suggests that the processes through which cultural (or symbolic) injustices tend to arise are fundamentally "rooted in social patterns of representation, interpretation and communication". Developing this, Fraser identifies three interrelated practices commonly associated with cultural injustice. These include non-recognition which renders groups invisible "via the authoritative, representational and interpretative practices of one's own culture" and disrespect, the routine malignment "in stereotypical public cultural representations and/or in everyday life interactions". Both are fundamental to the overarching injustice of cultural injustice, of "being subjected to patterns of interpretation and communication that are associated with another culture and/or hostile to one's own" (Fraser, 1995, p. 71). In short, in a democratic society, equal status must be given to individuals and groups, an idea that should saturate its practice as well as being apparent in its cultural outcomes.

While these dimensions overlap, the paper uses each in turn to discuss how public art has been used to foster social inclusion in the city. Collectively, they provide pointers to what, in public art terms, would define an inclusive city, as one giving expression to the multiple and shifting identities of different groups, as indicative of presence rather than absence, and of avoiding the cultural domination of particular élites or interests. Such a mapping represents an ideal. The reality of 
cities, their social diversity and fluidity, and the power relations underpinning the uses of public art challenge the ability of meeting such ideals.

Our approach is empirical, drawing on specific examples of how public art has been used to foster social inclusion in the city. The case studies have been chosen to demonstrate the range of issues surrounding inclusion and public art. No claim is being made that the selection is either definitive or wholly representative. Due to the lack of evaluations into the success, or otherwise, of public art projects, it is difficult to compose a representative selection of good or bad practice and whereas iconic or controversial projects may receive critical and media attention, those at community level are often neglected in this respect. There are many examples of public art and it is difficult to choose examples without appearing anecdotal. Therefore, a deliberate attempt has been to consider a range of known works from Europe and North America many of which, in process as well as product, have become very influential contributing to subsequent debates surrounding notions of inclusion. That the works discussed are in a number of cases relatively well-known examples of public art should not be taken to imply that they necessarily reflect what might, in social inclusion terms, be considered as exemplars of good practice. Rather, their selection has been made to demonstrate the variety of public artworks and of the modes through which intervention can be sought. Further, the focus on process allows us to investigate how inclusive are practices, emphasising the key issue of ownership. Studies elsewhere on community participation have underlined the significance of ownership as shaping the value in which democratic participation is held (in the different case of housing, see Goodlad et al., 2001). Such a sense is apparent within the different 'stages' through which participation takes places from agenda setting to policy formulation to implementation, the critical factor being the extent to which, and how, citizens are included in the processes.

\section{Public Art Production and Cultural (In)justice}

\section{Non-recognition: Reclaiming Place and Recognising Past}

When working on participatory projects, artists are frequently dealing with communities who have been marginalised in mainstream urban histories. There is a general sense that they have been made invisible within the cityscape and therefore a key strategy in overcoming this sense of nonrecognition is to render their history visible in some form. The very visibility of public art and its traditional monumentalism and aggrandising of civic 'heroes' mean that it is a prime vehicle through which minority groups can affirm their history and physically mark their place within the layered histories of the urban space-the past being a keystone upon which to build for the present and future. As Ron Griffiths has noted

an important part of the experience of exclusion is a weakened or non-existent sense of identity and pride. A key step in integrating excluded populations into the social mainstream, therefore, is to assist them to find their voice, to validate their particular histories and traditions, to establish a collective identity, to give expression to their experiences and aspirations, to build self-confidence. (Griffiths, 1999, pp. 463-464).

There is a pervasive trend when working on such participatory projects to seek to, as Griffiths termed it, "validate their particular histories". Often the recognition of a particular community and their association with a specific place are integral to this process. Early and influential work in this area was undertaken by the non-profit arts organisation The Power of Place, which aims to create memorials or presences in the urban landscape of Los Angeles to those 'forgotten' by dominant histories-for example, the Black slave and midwife Biddy Mason (Hayden, 1995, pp. 169-187; Miles, 1997, pp. 177-178). Commissioned by the Community Redevelopment Agency and with funding from 
various organisations including the National Endowment for the Arts, The Power of Place liaised with the community and produced books, posters, a photomural and a 'Window of Memories' showing Betye Saar's Nostalgia collages. In addition, Sheila Levrant de Bretteville produced a permanent installation Biddy Mason: Time and Place on the site of Mason's homestead. Such modest interventions into public space restore and pay homage to the dignity of minority figures and yet, perhaps inevitably, are tainted with an air of nostalgia just as other monuments resound with patriarchal hegemony.

With some projects of this nature, there is an air of opposition, of reinstatement, of stressing an alternative canon when, perhaps, there is a need to yield more towards a 'differencing the canon', as the art historian Griselda Pollock has termed it (Pollock, 1999). As Dorothy Rowe explains

Pollock implies that 'differencing the canon' is not about the replacement of one set of canonical works by another as devised by feminism, but that it is a rather more nuanced activity that continually questions the borders of knowledge, desires and power (Rowe, 2003, p. 28).

There is a danger amongst schemes that aim to resurrect tangibly histories that they will iconicise or nostalgically myth-make in a retelling of history. Against this, the nature of the contemporary community requires careful consideration, necessitating a questioning of its relationship with a particular place and its links, if any, with the past. As Lucy Lippard has stated

Like the places they inhabit, communities are bumpily layered and mixed, exposing hybrid stories that cannot be seen in a linear fashion (Lippard, 1997, p. 24).

Replacing non-recognition with recognition seems somewhat simplistic and making the invisible visible, too literal. Although through its sheer visibility public art seems an ideal tool through which to restate a presence in the urban landscape and, by association, its history and evolution, it is here that the artist has the potential to intervene, to interact with the contemporary community, to research and reveal the past in a subtle and intuitive manner. In this, The Power of Place has sought to insert itself sensitively, creating varied forms of artwork and subtle inscriptions in the cityscape. To see its work as insular examples is to undermine the ethos of the project. Besides Biddy Mason, other projects have included the preservation of historic buildings in the 'Little Tokyo' district of the city (Hayden, 1995, pp. 210-225) and such places create a dialogue through which a sense of the urban experiences of minority communities can be felt.

Although a monument or memorial to a significant but neglected historical figure can have wide resonances for a minority community and its recognition at large, working with a collective history poses a different challenge. Recovering a neglected collective history that has little or no presence in hegemonic histories or traditional museum archives almost forces an artist to take an ingenious approach. The onus is specifically on the communal, the mutual endeavours and the shared struggles. To commemorate just one individual would undermine the raison d'être of the project. One innovative response to such a situation was demonstrated in Andrew Leicester's state-funded project Prospect V-III (1982) in Frostburg State College, Maryland. Again emphasising the importance of process, Leicester spent time visiting mining sites and interviewing miners and their families. The resultant work took the form of what could be termed an alternative kind of museum, built in the style of 19th-century mining architecture and housing artefacts donated by the miners' families. Furthering their involvement, members of the local community chose to provide guided tours, which suggested that they had taken 'ownership' of the work. As well as reinstating a presence in the landscape and recovering a lost history, Leicester made the project relevant for the contemporary community. Leicester's inclusive process and the resultant artwork have the potential to function as inspiration for those wishing 
to remember excluded communities in contemporary post-industrial cities.

In dealing with public art, it is tempting to focus on place-specific works as public art tends to be associated with particular places and situated in certain sites. However, just as notions of community can transcend specific geographical locales, so can artworks themselves. In 1991, the V\&A initiated the Shaimiana: The Mughal Tent programme devised by Shireen Akbar and aimed at south Asian women and their children. Although encompassing broader aims than just recognition, Akbar's project saw inclusion as a challenge facing society at large and also, sensitively, as an internal cultural issue as Asian children were perceived to be losing a sense of their south Asian heritage as they became integrated into British culture. Community groups from across Britain were brought to the V\&A to examine aspects of south Asian history using the museum's collection. As a result, they produced a textile panel using traditional methods but reflecting contemporary cultural concerns. The panel was then displayed as part of a tent, inherent in which were ideas of home, transience and travelling (Rowe, 2003). As well as opening the museum's collection to a wider community, the project brought together an immigrant ethnic group perceived as being isolated from mainstream British culture. Partly to help overcome this sense of isolation and to create dialogue between different female communities and cultures, those involved included non-Asian women and the project integrated a variety of religions. Therefore the project attempted to build connections across a marginalised group and cultivate relationships and awareness with other sections of society. The Mughal Tent became an international project and has been made accessible via the Internet, its impact rippling out to a much wider community altogether and its form challenging traditional conceptions of public art.

All of these artworks were inclusive in terms of their target audience and, crucially, their practice. They addressed communities that tended to be excluded from wider urban processes and, with them, created a tangible, if, in the case of The Mughal Tent mobile, marker of their presence. However, this is not an overt claim for recognition through mere visibility. They overcome Fraser's notion of non-recognition in a tangible but subtle sense, trying to increase awareness of marginalisation and commemorate histories in a manner meaningful for the present. In this, a meaningful, democratic process has been key to the sustainability of initiatives and apparent in the outcomes.

\section{Disrespect: Giving Voice, Countering the Stereotype and Rediscovering the Margins}

If giving voice through the vehicle of public art can be the means of drawing the invisible into the urban narrative, it also has a role in drawing in those citizens and spaces whose marginalisation stems from other causes. That is, marginalisation in the city is not just a product of being invisible. The poor, those living in deprived neighbourhoods, are not so much invisible as inaudible. Stigmatisation, the stereotyping of particular groups and the urban spaces they occupy, is a commonplace source of marginalisation.

The idea of giving a community a voice and overcoming preconceptions was at the core of Iñigo Manglane Ovalle's work TeleVecindario (1992-93) for 'Culture in Action', an outreach project devised by the non-profit arts organisation Sculpture Chicago (since merged into Chicago Department of Cultural Affairs' public art section). Curated by the influential curator and writer, Mary Jane Jacobs, 'Culture in Action' was a deliberate attempt to engage minority communities unfamiliar with Sculpture Chicago and the artworld at large. Rather than artists with an international reputation, those chosen were known for participatory projects and, in this instance, went through a two-year period of collaboration with minority groups (Drake, 1994, p. 13). The resultant artworks took various forms from an altered paint chart to a multi-ethnic festival to sculpture and chocolate bars. Despite the length of collaboration, criticism has been made that artists tended to be 'shipped in', therefore 
having little knowledge of the communities with which they were working (Hixson, 1998), and the value of the projects has been questioned (Karasov, 1996, p. 25). Still, three of the eight artists involved were Chicagobased, including Ovalle whose project was arguably the most successful in the sense of engaging with the local community.

Ovalle lives and works in the lowerincome, mainly Hispanic neighbourhood of West Town, an area riven by gang violence and the problems associated with social deprivation. Working with a community leader and a co-ordinator of a Schools Programme, Ovalle brought together a group of mostly Latino teenagers, some from rival gangs. It emerged that the teenagers felt misrepresented and stereotyped by the media and countering this became the impetus for their project. With the assistance of local video professionals, they formed Street-Level Video and produced a series of films of people in the community discussing a range of issues including gentrification, race and gangs. This not only formed links between various factions of the community but also bridged generations. The project culminated in a 'block party' where 71 monitors were placed outdoors and broadcast these dialogues to the public at large. Local residents voluntarily provided electricity from their homes and this wittily and symbolically furthered the notions of empowerment central to the project (Jacobs, 1995, p. 86). The party brought people from across Chicago into the neighbourhood, challenged preconceptions, and places of street violence became more neutral spaces for exchange and dialogue. Importantly, Ovalle's project was not simply a means to counter stereotypes and offer an alternative but homogenised narrative; instead, it involved a more perceptive communication of numerous identities within a community and encouraged dialogue both internally and with wider society.

A clear sign of the achievement of the project has been its sustainability; Street Level Youth Media remains active and the 'block party' is an annual feature. It is a moot point, however, whether this success is attributable to Ovalle's position as residentartist. Ovalle inevitably benefited from pre-existing connections and knowledge and yet, as Jacobs herself has noted, it is perhaps oversimplistic to presume that "you're making a significant work for a place by solely selecting people who are full-time residents of that place" (Drake, 1994, p. 13). It is possible to argue that bringing an outsider's point of view, a fresh pair of eyes free from any preconceptions, would be equally beneficial. Therefore, emphasis must, again, fall on the implementation of a process, which, in this instance, was democratic giving room for multiple voices to be heard.

The articulation of numerous identities in an artwork, however, can be problematic. Although Tele-Vecindario recognised the various facets of one community, mainly Hispanic, process becomes more complex when seeking to implement a democratic practice and produce an inclusive artwork within an extremely mixed neighbourhood. In such circumstances, one solution has been to facilitate a space for cultural exchange rather than impose an artificial, fixed vision of a community through a singular representation. When there is a shared sense of history, religion, nationality or even loss contributing to a sense of community, then it is perhaps easier to find a common theme or direction for an artwork than when a community is multicultural and diverse, and whose links lie in their residency on the same site and their situation as a minority within the larger social fabric of the city. In such a social context, claims that public art can contribute to, if not create, community cohesion, seem somewhat 'easier said than done' and misguided. As Ash Amin has argued

The distinctive feature of mixed neighbourhoods is that they are communities without community, each marked by multiple and hybrid affiliations of varying social and geographical reach, and each intersecting momentarily (or not) with another one for common local resources and amenities. They are not homogeneous or primarily place-based communities ... They are 
simply mixtures of social groups with varying intensities of local affiliation, varying reasons for local attachment, and varying values and cultural practices ... Mixed neighbourhoods need to be accepted as the spatially open, culturally heterogeneous, and socially variegated spaces that they are, not imagined as future cohesive or integrated communities (Amin, 2002, p. 972).

Echoing the sentiments of Hall and Robertson mentioned above, Amin argues that difference must be an integral part of the process towards inclusiveness. Recognising this, the arts organisation nva worked with the most ethnically diverse community in Scotland in Glasgow's Pollokshields district to transform derelict wasteland into 'The Hidden Gardens'. The gardens, in planting, planning and a series of artworks and events, aimed to reflect the horticultural influences of the various faith communities in the local area. Crucially, it aimed to be inclusive throughout from initial conception to the final realisation and subsequently (in its on-going management). It was a delicate and difficult process that involved dialogue with a number of communities. Key here, particularly in the process of initiating dialogue between the multiple communities, was the appointment of a community facilitator sympathetic to the needs of local groups. After learning about the area and its constituent communities, drafts for the project were successively discussed between groups and the artists and horticulturalists hired by nva (a consultancy firm specialising in the field). The participatory process was critical in which local groups were encouraged to assume that participation would influence the design and use of the space. In other words, by emphasising that participation would help to define the nature of the proposal, its implementation and, over the longer term, its running, the dialogue sought to encourage a sense of ownership and empowerment (Paddison and Sharp, 2003, p. 11). Although the gardens have restricted opening hours and this may raise questions as to their accessibility as a public space, since their opening they have proved a popular space of retreat in an area underprovided with open spaces. They have also become a tourist landmark, a positive development in bringing visitors to a part of the city otherwise off the tourist map, and for encouraging awareness of the ethnic diversity of the city. Yet, by being drawn into the rhetoric of the city's marketing promotionmulticulturalism as evidence of the city's promotional adage as 'The Friendly City'the development courts usurping the communities' sense of ownership. By this token, social inclusion is not just an aim of urban regeneration; it can become also a means for projecting the city's image.

The increasing importance given to community liaison in such permanent projects requires careful consideration: there can be a substantial difference between consultation and inclusionary practices fostering empowerment (Burns et al., 1994; Young, 2000). The difference between seeking an opinion, which might be little more than a public relations exercise, and involving communities more fundamentally in the deliberative process culminating in decision-making itself can have profound impacts on the creation and reception of a work and the community at large. One example is Portsmouth City Council's commissioning of Peter Dunn, most famous for his association with the Art of Change, to produce an art scheme for a sports and community facility in a deprived neighbourhood. Dunn collaborated with the community, other artists, architects and landscapers to transform the environment based on the principles of Agenda 21. The site was given unique identity through the design of earthworks, boundary walls, narrative pathways and wall hangings and its distinctiveness was underscored by the landmark sculptural work the Wymering Tree. Perhaps more significant than the development itself, however, was the community involvement. A community board took control of the management of the project so they were not only given a voice in the aesthetic nature of the site, but also played an integral and decisive role in the process and the implementation 
of strategies. The community involvement in both the artistic and policy processes of the project demonstrates the potential for the community to determine the nature of the artwork produced and be integral to the changes taking place around them. This works well at community level, but the implementation of such a process city-wide, where public art is increasingly being used as a promotional tool, is more problematic.

The incorporation of major public art projects into regeneration schemes has become a key factor in rebranding a city's image, especially in post-industrial towns-in the UK, Glasgow, Birmingham and Gateshead are principal examples where culture, including public art, has been vaunted as a force in changing each city's fortunes. The Angel of the North by Anthony Gormley has become iconic not only for Gateshead but also indicative of the power that public art can yield as a tool in changing the perception of the 'postindustrial' to the 'cultural' city. It is the figurehead for a scheme throughout the city that has used public art for a variety of purposes (see Figures 1-3).

The Riverside Sculpture Park has reclaimed a derelict industrial site and used it as a means to bring art to the public. Similarly, Windy Nook by Richard Cole is a prominent but sympathetic land art feature that has transformed a colliery slagheap into an environmental art-site to be used by the community. The public also encounters art in a series of schemes at the Queen Elizabeth Hospital that explore the potential of the arts in

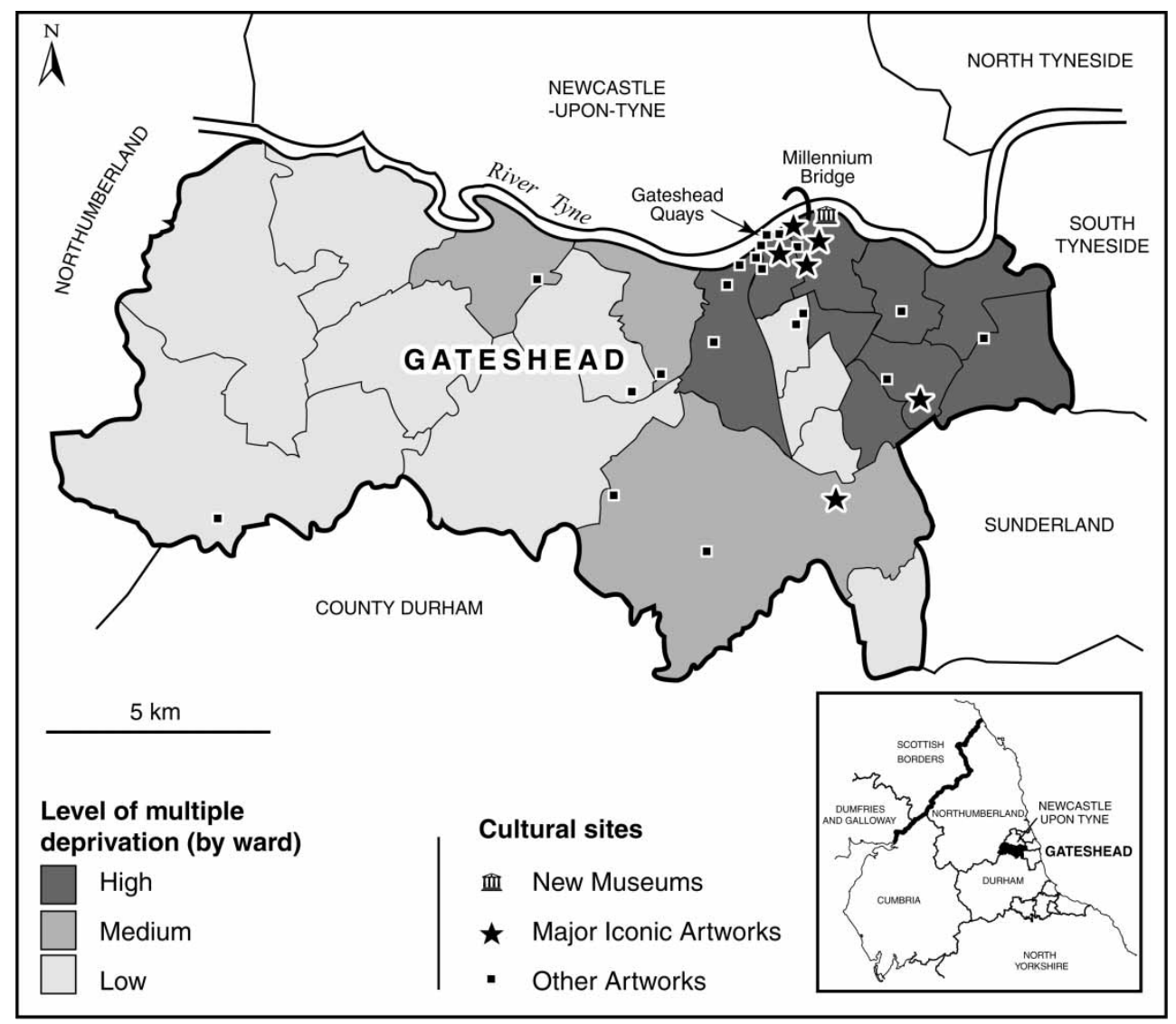

Figure 1. Public art and deprivation in Gateshead. Projects have focused on waterfront sites although these include several of the most deprived wards (defined on basis of socioeconomic and health indicators). The council has also sought to distribute public art works more widely in Gateshead. 


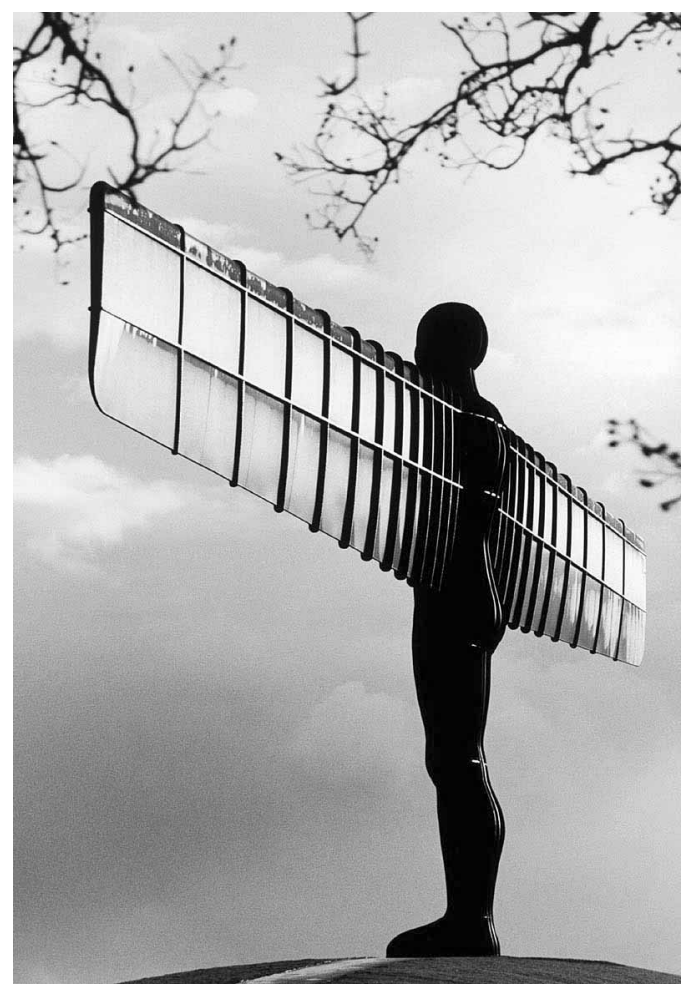

Figure 2. Angel of the North (1998), by Antony Gormley. Photograph courtesy of Gateshead Council.

healthcare. Alongside iconic pieces by renowned artists, including Richard Harris, Andy Goldsworthy, Colin Rose and Richard Deacon, the public is invited to participate in events such as the annual sculpture day. The iconic and community aspects are not wholly mutually exclusive, however, and over 1400 children at 30 schools were involved in work connected with Gateshead's Angel. Many of the artworks are concentrated in areas of social deprivation and this highlights how public art has been used as a tool to reaestheticise areas within a city as well as the city at large. Implicit in this is the notion that public art can bring economic and social benefits alongside the aesthetic. Their award-winning public art programme has evolved alongside several more iconic projects within the city centre including the conversion of old flourmills into the Baltic Arts Centre, the development of Gateshead

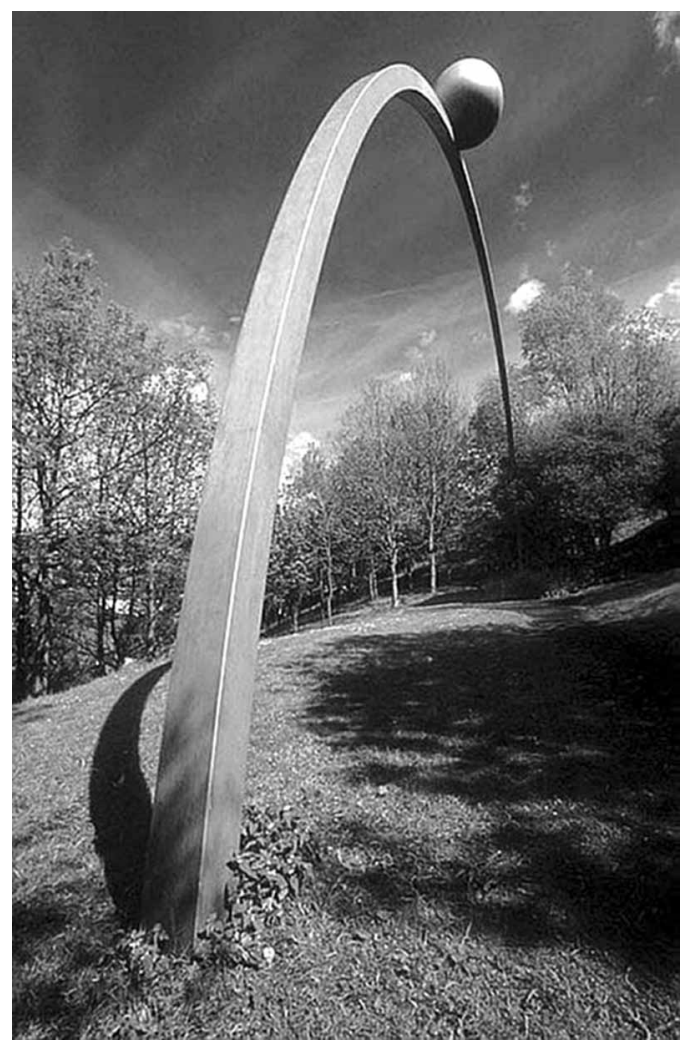

Figure 3. Rolling Moon (1998/90), by Colin Rose. Photograph courtesy of Gateshead Council.

Quays and the building of the Millennium Bridge linking Gateshead's Quays to those recently refurbished in Newcastle. Together, the cities, which made a joint (but unsuccessful) bid for the 2008 European Capital of Culture nomination, aim to create a centre for cultural excellence with prestige residential and leisure developments. Here, the combination of iconic visual emblems, art and architecture, have gone some way to crafting the city as a cultural landscape.

It must be recognised that, although many policy documents and participatory projects appeal to overarching terms such as 'community', 'identity' and 'place', the general conformity of sentiment belies the complex situations facing artists, cities and their multifarious communities. The general lack of evaluative measures in community programmes means that it is difficult to outline measures of 'good practice', make affirmations of 
what constitutes a 'successful' intervention or add credence to the claims made about public art's social impact. As urban regeneration initiatives attempt to transform cities, public art itself seems to be undergoing a transformation, moving from traditional civic monumentalism towards seeking a more socially inclusive and aesthetically diverse practice. Rather than impose or enforce inclusion, it has to be intuitively and sensitively sought, recognising the importance of difference and the vitality in diversity. When working with inclusive projects, the emphasis seems to lie with the process rather than the product. This may raise questions about the artist deferring to the community, artistic integrity and aesthetic quality. It challenges institutions and funding bodies to consider the worth of intangible as well as tangible outcomes, temporary as well as permanent products. Traditional notions of the artist as creative genius have to be reassessed and the artist has to find a position between ingenious creator and creative facilitator. The use of culture in the reastheticisation of the urban environment also brings the danger that areas, as they become more attractive places in which to live and work, experience gentrification. Communities, places and process are integral but intricate components of the artwork. The extent to which each is considered and the manner in which their inclusion is sought and managed has profound implications for the aesthetic and social outcomes of the completed project.

\section{Cultural Domination and the Arts of Resistance}

Works such as Gormley's Angel of the North or monumental architecture that signal a city's distinctiveness (for example, London's 'gherkin' building, Glasgow's Scottish Exhibition and Conference Centre, Birmingham's mirrored Selfridges store or the competition between global cities to own the world's tallest building), demonstrate the importance of reworking the skyline as an attempt to refashion the image of the city as a whole. Such developments are clearly intended to enhance the image of the city, repackaging it as a commodity for consumption in the postindustrial age (see Urry, 2001). Public participation is generally not high on the agenda in this form of 'authoritarian populism', a Victorian image of city leaders knowing what's best for the city and for its citizens. In claiming to be a signifier for the city as a whole, of course, it hides the inclusions and exclusions inherent in any singular vision for a community.

Furthermore, the ever-increasing use of notions of inclusion through public art works in urban regeneration efforts makes one important assumption: that these processes are compatible. However, as Malcolm Miles has argued, due to the very nature of capitalist development, it is not always possible to draw public art into development in a way that is equally beneficial to all parties

Developers do not develop in order to construct the 'city beautiful'. They construct the city beautiful in order to conceal the incompatibility of their development with a free society (Miles, 1997, p. 130).

From such a perspective, any sense of involvement with the process then is inherently linked to collusion with forces that are fundamentally more interested in capital investment or maintaining social order than with improving the lives of residents of a city. Certainly, critics of Glasgow 1990 City of Culture were quick to point out the benefits to industry and investment in the city but that, for the majority of Glaswegians, nothing had changed (Boyle and Hughes, 1991). Not dissimilar criticisms have arisen in other cities as Broudehoux (2004) has demonstrated in The Making and Selling of Post-Mao Beijing. For others, there is a problematic of where public space is-in contemporary cities, the spaces where people meet are increasingly being commodified so making truly grassroots expressions in public space more difficult (Mitchell, 2003; Phillips, 1988). Therefore, it is debatable whether public art can ever be wholly inclusive, especially within urban regeneration where complex factors of public space, commercialisation and commodification, and cultivating 
an iconic cultural cityscape are intimately entwined. In this environment, public art, rather than participating in an inclusive agenda, can function as an oppositional or resistant force, highlighting excluded groups and visualising protest to dominant regeneration schemes.

\section{Resistance and Regeneration}

As opposed to the usual iconic permanence of art prominent in regeneration schemes, these interventions tend to be temporary and take a variety of forms.

For instance, the redevelopment of the London Docklands in the 1980s stimulated a battle for land and for visibility that was articulated through the nature of the visual landscape in art. The reimaging of the landscape, however, neither accepted nor accommodated all: local people felt that not only had they been dispossessed by the new developments but that they had been written out of this new landscape. Developers talked in terms of a 'virgin site' for development, erasing the resident population and those who had lived there in the past. The gentrified landscape romanticised a particular part of the area's history, focusing on middle-class cultures of consumption rather than workingclass cultures of production from the area (just as was later to occur in Glasgow where the rewriting of the city's landscape in terms of Charles Rennie Mackintosh and the Glasgow School of Art were seen to be at the expense of working-class cultures of 'Red Clydeside' and social struggle (Boyle and Hughes, 1991)). In addition, the new developments privatised space: waterfront walks became private property, high walls were erected around new development and the Docklands Highway ran through the Trade Unions building and local housing. One of the attempts to rewrite silenced community back into landscape was through the Docklands Community Poster Project which visualised narratives of community presence back into the redeveloped landscape through the use of billboards showing aspects of local history and identity, and expressing people's opinions of the development (Dunn and Leeson, 1993; Bird, 1993). These large posters displayed local versions of place in the landscape of regeneration, refusing to be hidden behind the reworked image. They aimed to write people and their history into the landscape rather than an aesthetic focused around property and heritage.

Other expressions of resistance to this redevelopment took the form of vandalism and graffiti. To some, as a form of cultural expression, graffiti are giving a voice to those who do not own the capital and buildings upon which billboards are mounted, and so cannot legitimately write up their messages onto the urban landscape. It is a way in which those who have been passed over by regeneration can write themselves back into the landscape, refusing to conform to the new urban order. Some feel that, although we are "as much creatures of the public realm as the private realm, we find ourselves silenced whenever and wherever we might create meaning to share with others" as public space is tightly controlled by capitalism and the capitalist state (Luna, 1995, np). Graffiti and culture jamming (the addition of slogans to billboards and advertising to subvert the intended message) draw attention to the power and meanings inscribed into the urban environment. Its artists are attempting to denaturalise the taken-for-granted landscapes that we each use on a daily basis, asking us to be aware of the power relations that work through this mundane space (Cresswell, 1998; Deutsche, 1996).

Some have incorporated this politics of opposition into their approach to creating art in the city-for instance, Krystof Wodiczko, particularly in his series of Projections. These nighttime projections of images onto prominent buildings and statues were used to challenge the meanings of the landscape elements that dominate contemporary cities. Thus, in projecting a swastika onto the South African embassy in London 1985, missiles onto war memorial columns and images of disability onto heroic statues, Wodiczko was asking the viewer to think about what it is we choose to memorialise in our landscapes, 
and which experiences, events and narrations of history are silenced (Wodiczko, 1999).

Artists such as Wodiczko also seek to represent those in the urban landscape who cannot represent themselves. As the Docklands example showed, there are many who are marginalised by processes of redevelopment, or who are displaced by the processes of regeneration (Smith, 1993). Wodiczko developed the Homeless Vehicle Project, a mobile vehicle for homeless people to use to sleep, wash and keep their belongings in. It made homeless people visible, drawing them out from their naturalisation as an accepted (if unfortunate) part of the modern urban landscape (Smith, 1993). The vehicle became a talking-point between pedestrians and the homeless, and its consciously missile-like design made comparisons between the US government's spending on social welfare and defence unavoidable. Michael Rakowitz similarly exposed the relationship of homelessness to urban development in his ParaSITE series which placed inflatable constructions over heat vents of buildings to provide homeless people insulated and private spaces where they could exist-parasitically-alongside the modern buildings. As he put it

While these shelters were being used, they functioned not only as a temporary place of retreat, but also as a station of dissent and empowerment; many of the homeless users regarded their shelters as a protest device ... The shelters communicated a refusal to surrender, and made more visible the unacceptable circumstances of homeless life within the city (Rakowitz, 2000, pp. 234-235).

Clearly, the homeless vehicle project and ParaSITE are not solutions to homelessness and the other negative social products of urban redevelopment. Their role as a cultural product of the city is to make visible the naturalised relationships that are established through the built form, to amplify "the problematic relationship between those who have homes and those who do not have homes" (Rakowitz, 2000, p. 235). As Fraser argued, amongst the debates surrounding the use of culture in urban regeneration attention needs to be paid to economic redistribution. Works like those of Wodiczko and Rakowitz highlight the problematic notions of inclusion in schemes of urban redevelopment.

\section{Problems of Process}

In practice, the division between public art initiated by authorities and grassroots approaches is much messier than it may seem. State-sponsored projects now almost always include a community element, while some artists who have previously worked with grassroots projects now work for both 'top-down' and community-led projects (for instance, the Art of Change). Critical artists claim that their work establishes a conversation between the spaces and the people who inhabit them. This is perhaps questionable: who really has a conversation? To what extent does this rely upon an élitist language of art and politics? On the other hand, art that is developed through the effort of local governments and other local development agencies does not necessarily turn out the way that was intended, alternative meanings and practices might emerge, people can reinscribe images with personal and local meaning. As mentioned earlier, this makes clear the importance of understanding the processes through which public art is made and placed within different parts of the city. When this fails, it can promote interesting debates over issues, but can also be intensely demoralising for the communities involved.

The complexity of the processes through which public art is made meaningful to different communities is perhaps most (in)famously seen in debates over Richard Serra's Tilted Arc (see Senie, 2002). The work was sited in Federal Plaza, Manhattan in 1981 as one of the last in the Kennedy-inspired Artin-Architecture programme to bring art into public spaces. Serra, an artist known for his 'anti-environmental' works, saw his sculpture as challenging the bourgeois bureaucratic spaces that usually contextualise the display of artwork-in this case, the sanitised, 
alienating square created by the meeting of two blocks of the Federal Building. The sculpture was constructed from Corten Steel, 120 feet long, 12 feet high and 2.5 inches in width. Covered with a surface of brown rust, Tilted Arc bisected the square, tilting off both its horizontal and vertical axes (Blake, 1993, p. 261). Serra challenged this order through a sculptural form that refused to offer a reconciliation of architecture and sculpture but instead revealed "a conflicted space that lays bare its internal divisions to its inhabitants" (Blake, 1993, p. 254).

There was a great deal of opposition to the sculpture. Some saw it as too oppressive, too big, too dominant or too rusty. New Reaganite federal leaders used this popular opposition to push for the removal of the artwork as part of an attack on the National Endowment for the Arts and radical art more generally. These right-wing opponents assumed that public opposition meant that, like them, the public rejected Tilted Arc in favour of the previous environment of the square. This was not quite the case. On the whole, it appeared that public opinion was in agreement with Serra's critique of the alienating square but not the aesthetic form he had adopted. They found the sculpture as sterile as the space it sought to subvert. One worker said "I do not care to be challenged on a daily basis by something designed to be hostile" and another concluded that "What we need ... is something to enliven our lives, not something which reinforces the negativity of our work lives" (Blake, 1993, p. 284).

This raises important questions about artists' responsibility to community. Some of the most artistically successful and challenging work may not be easy to live with. While it is possible to walk away from a work in a gallery, once works are incorporated into lived spaces they cannot always be avoided.

What the Tilted Arc controversy forced us to consider is whether art that is centered on notions of pure freedom and radical autonomy and subsequently inserted into the public sphere without any regard for the relationship it has to other people, to the community, or any consideration except the pursuit of art, can contribute to the common good (Gablik, 1995; quoted in Miles, 1997, p. 90).

For post-Tilted Arc work, there has been less in the way of 'parachuted in' artists (but see Public Art Review Special (July/August 1998) Public Art: Fail) and, instead, context and community involvement are increasingly important. However, this is not to say that these tensions have disappeared (regardless of how inclusive the intentions are).

Furthermore, while properly managed processes can help to maximise a sense of ownership and even empowerment, if these processes are interrupted for whatever reason this can have negative consequences for the communities involved and for future attempts at community participation. An example of this was the Five Spaces, public spaces developed by artists and architects with communities around Glasgow as part of Glasgow 1999 (UK City of Architecture and Design). Although the Five Spaces were to be one of the 'flagship' events, when 1999 arrived they enjoyed a much less significant public profile than the other spectacular (and centralised) events, Homes for the Future and the design centre the Lighthouse. While the Lighthouse took nearly half of Glasgow 1999's budget of around $£ 27.5$ million, the Five Spaces was allocated less than onetenth of it. Media coverage of the Spaces was similarly less prominent than for the Lighthouse and Homes for the Future, so that, when asked at the end of the year, very few visitors, Glaswegians or even design professionals could name the Five Spaces as a prominent feature of the programme (DTZ Pieda, 2000).

A 'trial run' of spaces was implemented in 1997, when the artists took up their residencies and developed plans for the spaces. This aimed to develop a process through which communities could become involved in the selection of the spaces and the kind of work to be included. Each of the designated communities was located around the city, often in challenging environments. For some, the 
excitement of the Five Spaces was that, for the first time, the communities themselves were being asked for what they wanted rather than 'experts' telling them what they needed. Process was central to this project to ensure that there was community involvement-and therefore hopefully a sense of ownership - in the resulting spaces. Initially, there were to be over 20 of these spaces chosen by Housing Associations around the city. The initial cut took the number to 15 , then to 11 and then, well into 1998, the number was reduced to 5. For those who had been expecting their space to be developed, this was a major blow and perhaps reinforcement of the sense that their community was marginal to the city. Even for those communities which did have their spaces developed, the culture of uncertainty and experiences of being let down before meant that community leaders were unwilling to involve the community until the funding was absolutely assured by which point there was not sufficient time for proper participation.

Glasgow 1999 were determined that all the spaces would be delivered in 1999 (all but one were) and so they put in place a property management firm to deal with the arrangements of making the space. Here, institutional power heavily influenced the process-governance framework. The day-to-day ownership of the project was taken away from the Housing Associations for the sake of efficiency. Many Housing Association members felt that this pushed them out of the decision-making process and there has consequently been a loss of ownership, which has impacted the maintenance and management of the Spaces. Long-term problems are emerging because of this interruption of the process and lack of consideration to sustaining the SpacesGlasgow 1999 did its job and disbanded whereas the Spaces remain. The Housing Associations were not consulted about small, everyday issues and consequently, in one instance, the landscaping in one of the Spaces has been easily vandalised. Two years' labour was arranged for upkeep, but now it is up to the Associations to make arrangements, which it appears some cannot manage, or, as a result of their exclusion from the decision-making process, choose not to.

A great deal of the good that was done through these projects-of bringing people in to feel a sense of communal ownership, of making networks and so on-has been undone. Harding explains the problems that emerge when acts of vandalism are not immediately righted-and here we could also add other forms of decay such as flooding, breaking of light bulbs and problems with water features, all issues plaguing the Five Spaces.

When this happens, what was initially a focus of local pride quickly degenerates to the point where people become even more disheartened than they were before. Rectifying the damage done by vandals immediately sends out a clear message to people in deprived areas that their welfare is just as important to the authorities as the well-being of people living in affluent circumstances (Harding; quoted in Gordon, 2002, np).

However, leaving things in decline reinforces the image of a community in similar trouble. The story of the Five Spaces emphasises the importance of good process for the success of public art, but also makes clear just how fragile process can be, that it is "seemingly capable of derailment at any juncture for a variety of reasons" (Nikitin, 2000, np).

The infamy of the Tilted Arc controversy, and others like it, has meant that community involvement and consultation are now central to the process of siting and producing works. However, this does not mean that inclusion is necessarily achieved. Quite how it is that 'the community' should be involved can, in itself, become an exclusionary practice. Often, the same members of the community become involved and consequently others may feel further marginalised in light of these activists' participation. There is also often a spatial and temporal essentialism in defining community. While city-centre art works are seen as serving the whole city, when attention turns to public art in more marginal areas, 
there is a sense of a number of unchanging and spatially discrete communities existing in a neat patchwork across the city. Inclusive approaches to designing public art-workshops, meetings and so on-can ensure ownership by those in that community and hence encourage care and lessen the likelihood of vandalism. However, as communities within cities are not water-tight spaces, this will not prohibit members of nearby neighbourhoods from (mis)using the public art too. Similarly, approaches that draw in community members at one time cannot ensure that future community members will still feel a sense of ownership over the product. As Senie (2003) suggests, this requires a critical rethinking of notions of site-specificity. She argues that as "a public site invariably undergoes seasonal and/or developmental changes, any work would logically have to be frequently or periodically redesigned to remain specific" (Senie, 2003, np). Once again, process, here defined in the long term, is central to success.

Perhaps too much is expected of public art. Too quickly, a number of critics have blamed these projects for not making enough of a difference. John Calcutt ridicules such expectations

Expecting public art to solve social problems is either naïve or cynical. In attempting to critically evaluate public art projects such as Five Spaces we should bear in mind that fact that the production of art arises within and is subject to many of the same social, political and economic pressures that affect its reception (the increasing privatisation and commercialisation of the public sphere, the fragmentation of unified social and political agendas into the specialised concerns of competing interest groups-each with their own social and cultural priorities, and so on) (Calcutt, 2002, p. 11).

Calcutt is not suggesting that public art such as the Five Spaces is somehow put beyond criticism, but that it is impossible for such works to transcend their social, political and, perhaps most importantly in the case of urban regeneration, economic context. This again points to a need for developing appropriate forms of evaluation. Rather than an evaluator's postproduction critique, however, there is a clear need for evaluation to take place throughout the process-from the inception, through the process to the final work. Assessment needs to be made of the process and its success in being 'inclusive' as well as the governance structure through which it is implemented. Such evaluation has the potential to ensure that a meaningful process would yield a meaningful outcome and that problems of process are overcome.

\section{Conclusions}

In a critique of the uses of culture in the reinvention of Barcelona that is all the more refreshing precisely because of the frequency with which the city is cited as a role model, Balibrea (2001) has argued that the consensus over the city's development needs to be challenged. As significant as have been the achievements of the city, and particularly of the municipal government, in physically transforming the metropolitan area including run-down inner-city areas as well as the waterfront and harbour, and in bolstering its economic competitiveness, particularly as a tourist and convention centre, such achievements have been accompanied by increasing social polarisation and the development of peripheral estates whose residents have endured a worsening quality of life in both the 1980s and 1990s. The absence of any significant dissent ('culture wars') particularly over flagship projects may be read as support for change. But it may also be read as false consciousness in which "the production of consensus [as] the principal means of legitimising domination and of co-opting potentially critical citizens" has been able to convince the citizens that their interests are equivalent to those of dominant economic classes (Ripalda, 1999; Esquirol, 1998; quoted in Balibrea, 2001).

While such alternative interpretations can themselves be challenged, their value lies in unmasking the rhetoric that surrounds the 
use of culture-including the benefits claimed for public art-in urban regeneration. Here, the 'Barcelona model' represents something of an extreme precisely because of the frequency with which it is cited, although exemplars of 'good practice' elsewhere are routinely identified as 'success stories'. For urban regeneration agencies, the search to repeat the 'Guggenheim effect' has become a mantra through which the reinvention of the city is to be realised within which public art, and particularly iconic design, occupies a critical position.

As the literature attests, it is too easy for both policy-makers and academics to focus disproportionately on the more spectacular, particularly the iconic, in its ability to reinscribe place. A blinkered gaze risks the failure to identify the different scales at which public art has come into play just as it tends to give emphasis to particular representations of it. As various examples have demonstrated, the use of public art is no more confined to the major cities as it is only to those spaces in them whose (re)valorisation has become part of the hegemonic project of fashioning the competitive city. In the interstices-in those places and spaces which are 'outside' the dominant discourse of international competitiveness that characterises the big city-the recognition of the contribution of public art to the reinscription of local place has become commonplace through the work of artists and community groups, as well as by the state acting through local agencies mindful of the agenda of inclusion.

It is important to remember here that, regardless of the scale and type of intervention, the installation of public art within the urban fabric is inevitably a political exercise. Thus, as Jameson has argued, buildings

interpellate me-[they] propose an identity for me, an identity that can make me uncomfortable or on the contrary obscenely complacent (Jameson, 1997, p. 129).

Much the same could be said for public art. The roots of this effect lie in its visibility, which in turn influences how we perceive the urban environment. Admittedly the influence of agency at this juncture means that how we perceive and interpret the interposition of public art varies as Jameson recognises and as was apparent through the Donald Dewar statue. Inevitably reactions to public art will vary. But even amongst those whose reaction to public art is more passive or 'complacent', its effects on the definition of the self and the self as citizen are real, if unarticulated.

The power of interpellation of public art is both a source for consensus and conflict within the reinscription of place. Within official discourse, the benefits of public art are expressed in its ability to instil civic pride and to contribute to local distinctiveness, yet the ability of public art to be seen as at odds with its intended symbolism emphasises its contentious nature. The play of inclusion in public art operates at two interconnected levels in the ways in which it is read as part of city space and the processes through which it is implemented. Sufficient experience exists to demonstrate that the two are connected, suggesting that a sense of ownership is a key component of inclusion. Yet neither is fixed precisely because of the multiplicity of ways in which public art is read and the fluidity of urban societies that defy the unity of community.

As much as this is suggestive of the importance of participation within the process of the production of public art, its advocacy will need to take account of the problems typically encountered in its practice. How local participation is structured to give adequate recognition to different local groups and how deliberation is conducted to ensure that these interests are able to have their voice heard and listened to are both fundamental to the practice of inclusive democratic processes. In both, experience of local participation highlights the problems likely to arise: the extent to which it can be dominated by a relatively small number of local activists, the reluctance to become involved and the problems in ensuring that meetings are conducted on the basis of equality and mutual respect and recognition.

Even, then, in the interstitial banal spaces in which everyday life is locally lived within cities, the installation of public art needs to 
be sensitive to local diversity. Its use needs to be aware that inclusive democratic practices, far from producing consensus-through which some common sense of local pride can be produced amongst diverse groupsmay become an agonistic process. The exercise of participatory democracy through recognition and respect and the avoidance of domination opens up the space for conflict reflecting the diversity of local voice. The reinsertion of public art in the city reveals how its use, and the language through which it is advocated, can be appropriated, no more so than in those revalorised spaces that are identified as key to the (re)definition of the competitive city. It is in the banal urban spaces in which everyday life is constructed and experienced in particular that the advocates of public art have been able to argue (and demonstrate) how the insertion of public art can aspire to be inclusive as process if not necessarily as outcome.

Yet the capacity of public art to foster inclusion is at best partial, able to address symbolic more than it is material needs. Whether this means that public art has become an unwitting agent in the overprivileging of cultural justice at the expense of socioeconomic redistribution is a moot point. However, this argument not only exaggerates the influence of public art on economic regeneration, but is itself an overeconomistic interpretation of the meaning of urban citizenship.

\section{References}

AMERICANS FOR THE ARTS (ND) Animating Democracy Initiative: Profiles and Cast Studies-Tele-Vecindario (http://www.americ ansforthearts.org/animatingdemocracy/resource center/profiles_content.asp?id $=185 ;$ accessed 28 June 2004).

Amin, A. (2002) Ethnicity and the multicultural city: living with diversity, Environment and Planning A, 34, pp. 959-980.

Andersen, J. and Sirm, B. (Eds) (2004) The Politics of Inclusion and Empowerment: Gender, Class and Citizenship. Basingstoke: Palgrave Macmillan.

BALIBREA, M. P. (2001) Urbanism, culture and the post-industrial city: challenging the 'Barcelona
Model', Journal of Spanish Cultural Studies, 2(2), pp. 187-210.

BiANCHINI, F. (1999) Cultural planning for urban sustainability, in: L. Nystrom (Ed.) City and Culture: Cultural Processes and Urban Sustainability, pp. 34-51. Stockholm: The Swedish Urban Environment Council.

BIRD, J. (1993) Dystopia on the Thames, in: J. Bird, B. Curtis, T. Putnam et al. (Eds) Mapping the Futures, pp. 120-135. London: Routledge.

BlaKe, C. (1993) An atmosphere of effrontery: Richard Serra, Tiled Arc, and the crisis of public art, in: R. Fox and T. J. LeARs (Eds) The Power of Culture, pp. 247-289. Chicago, IL: University of Chicago Press.

Boddy, M. and Parkinson, M. (2004) Competitiveness, cohesion and urban governance, in: M. Boddy and M. PARKINSON (Eds) City Matters: Competition, Cohesion and Urban Governance, pp. 407-432. Bristol: Policy Press.

Boyle, M. and Hughes, G. (1991) The politics of the representation of 'the real': discourses from the Left on Glasgow's role as European City of Culture 1990, Area, 23(3), pp. 217-228.

Broudehoux, A. (2004) The Making and Selling of Post-Mao Bejing. London: Routledge.

Burns, D., Hambleton, R. and Hoggett, P. (1994) The Politics of Decentralisation: Revitalising Democracy. London: Macmillan.

CAlcutT, J. (2002) Rack and ruin: the misplaced aims of public art, Matters, 15, p. 11.

Cresswell, T. (1998) Night discourse: producing/ consuming meaning on the street, in: N. FYFE (Ed.) Images of the City: Identity and Control in Public Space, pp. 268-279. London: Routledge.

Czaplicka, J. J. and Ruble, B. A. (Eds) (2003) Composing Urban History and the Constitution of Civic Identities. Washington, DC: Woodrow Wilson Center.

Deutsche, R. (1996) Evictions: Art and Spatial Politics. Cambridge, MA: MIT Press.

DrAKe, N. (1994) Making it happen: a dialog with Mary Jane Jacob, Public Art Review, 10, 5(2), pp. 13-15.

DTZ Pieda Consulting (2000) Evaluation of Glasgow 1999: UK City of Architecture and Design. Glasgow.

Dunn, P. and LeEson, L. (1993) The art of change in the Docklands, in: J. BIRD, B. CuRTIS, T. Putnam ET AL. (Eds) Mapping the Futures, pp. 136-149. London: Routledge.

Esquirol, J. M. (1998) La frivoldad politica del final de la historia. Madrid: Caparros Editores.

Fraser, N. (1995) From redistribution to recognition? Dilemmas of justice in a post-socialist age, New Left Review, 212, pp. 69-93. 
FrASER, N. (1997) Justice Interruptus: Critical Reflections on the Post-socialist Condition. London: Polity Press.

GABLIK, S. (1995) Connective aesthetics: art after individualism, in: S. LACY (Ed.) Mapping the Terrain: New Genre Public Art. Seattle, WA: Bay Press.

Giddens, A. (1998) The Third Way. Cambridge: Polity Press.

Goodlad, R., Docherty, I. and Paddison, R. (2001) Citizen participation in urban governance. Policy Paper 4, Scottish Executive. Department of Urban Studies, University of Glasgow.

Gordon, G. (2002) When art goes public, Scotland on Sunday 16 June (http://news.scotsman. com/archive.cfm?id $=653692002 ;$ accessed 22 October 2002).

GRIFFITHS, R. (1999) Artists organisations and the recycling of urban space, in: L. NYSTRÖM (Ed.) City and Culture: Cultural Processes and Urban Sustainability, pp. 460-475. Karlskrona: Swedish Urban Environment Council.

Gunn, S. (2000) The Public Culture of the Victorian Middle Class: Ritual and Authority and the English City. Manchester: Manchester University Press.

Hall, T. and Robertson, I. (2001) Public art and urban regeneration: advocacy, claims and critical debates, Landscape Research, 26(1), pp. 5-26.

Harvey, D. (2000) Spaces of Hope. Edinburgh: Edinburgh University Press.

Hayden, D. (1995) The Power of Place: Urban Landscapes as Public History. Cambridge, MA: MIT Press.

Hixson, K. (1998) Icons and interventions in Chicago and the potential of public art, Sculpture Magazine, 17(5) (www.sculpture.org/documents/ scmag98/chicgo/sm-chcgo.htm; accessed 28 June 2004).

IMrIe, R. and RACO, M. (2003) Urban Renaissance? New Labour, Community and Urban Policy. Bristol: Policy Press.

JACOBS, M. J. (Ed.) (1995) Sculpture Chicago: Culture in Action. Seattle WA: Bay Press.

JAMESON, F. (1997) Absent totality, in: C. D. DAvidson (Ed.) Anyone, pp. 124-131. Cambridge, MA: MIT/Anyone Corporation.

Karasov, D. (1996) Is placemaking art?, Public Art Review, 15, 8(1), pp. 24-25.

LACY, S. (Ed.) (1995), Mapping the Terrain: New Genre Public Art. Seattle, WA: Bay Press.

Lefebvre, H. (1991) The Production of Space. Oxford: Basil Blackwell.

Levinson, S. (1998) Written in Stone: Public Monuments in Changing Societies. Durham, NC: Duke University Press.

Levitas, R. (1998) The Inclusive Society? Social Exclusion and New Labour. Basingstoke: Palgrave Macmillan.
LIPPARD, L. (1997) The Lure of the Local: Senses of Place in a Multicentred Society. New York: New Press.

LunA, J. (1995) Eradicating the stain: graffiti and our public spaces, Bad Subjects, 20 (April) (http://www.hiphop-network.com/articles/graffi tiarticles/graffitiand publicspace.asp; accessed 28 June 2004).

Madanipour, A., Cars, G. and Allen, J. (Eds) (1998) Social Exclusion in European Cities: Processes, Experiences and Responses. London: Jessica Kingsley.

Marcuse, P. and Kempen, R. van (Eds) (2002) Of States and Cities: The Partitioning of Urban Space. Oxford: Oxford University Press.

Miles, M. (1997) Art, Space and the City. London: Routledge.

Mitchell, D. (2000) Cultural Geography: A Critical Introduction. Oxford: Basil Blackwell.

Mitchell, D. (2003) The Right to the City. New York: The Guilford Press.

Moulaert, F. Swyngedouw, E and Rodriguez, A. (2003) The Globalized City. Oxford: Oxford University Press.

Nikitin, C. (2000) Making public art work, Sculpture magazine online (www.sculpture.org/ documents.scmag00/april00/pub/pub.htm; accessed 27 July 2004).

PADDISON, R. and SHARP, J. (2003) Towards democratic public spaces. On-line papers, Department of Geography and Geomatics, University of Glasgow (http://web.geog.gla.ac.uk/online_ papers/rpaddison001.pdf; accessed 27 July 04).

PhILLIPS, A. (2004) Identity politics: have we now had enough, in: J. ANDERSEN, and B. SLIM (Eds) The Politics of Inclusion and Empowerment: Gender, Class and Citizenship, pp. 36-48. Basingstoke: Palgrave Macmillan.

Phillips, P. (1988) Out of order: the public art machine, Artforum, December, pp. 92-96.

Philo, C. and Kearns, G. (1993) Selling Places. Oxford: Pergamon Press.

PlazA, B. (2000) Evaluating the influence of a large cultural artifact in the attraction of tourism: the Guggenheim Museum Bilbao case, Urban Affairs Review, 36(2), pp. 264-274.

Pollock, G. (1999) Differencing the Canon. London: Routledge.

Rakowitz, M. (2000) ParaSITE, in: J. Hughes and S. SADLER (Eds) Non-plan: Essays on Freedom Participation and Change in Modern Architecture and Urbanism, pp. 232-235. Oxford: The Architectural Press.

Ripalda, J. M. (1999) Politicas Postmodernas: Cronicas desde la Zona Oscura. Madrid: Libros de la Catarata.

Rowe, D. (2003) Differencing the city, in: M. Miles and T. Hall (Eds) Urban Futures, pp. 27-34. London: Routledge. 
SASSEN, S. (2001) Cities in the global economy, in: R. PADDISON (Ed.) Handbook of Urban Studies, pp. 256-272. London: Sage.

Selwood, S. (1995) The Benefits of Public Art. London: Policy Studies Institute.

Senie, H. (2002) The Tilted Arc Controversy: Dangerous Precedent? Minneapolis, MN: University of Minnesota Press.

Senie, H. (2003) Responsible criticism: evaluating public art, Sculpture, 22(10), no page numbers.

Senie, H. (2004) Absence in presence: the 9/11 memorial design, Sculpture, 23(4), no page numbers.

SMIth, N. (1993) Homeless/global: scaling places, in: J. Bird, B. Curtis, T. Putnam ET AL. (Eds) Mapping the Futures, pp. 87-119. London: Routledge.
Smith, N. (1996) The New Urban Frontier. London: Routledge.

Urry, J. (2001) The Tourist Gaze. London: Sage.

Victoria AND Albert Museum (ND) Shamania Microsite (http://www.vam.ac.uk/vastatic/ microsites/shamiana/voice.htm; accessed 13 July 2004).

Whelan, Y. (2003) Reinventing Modern Dublin: Streetscape, Iconography and the Politics of Identity. Dublin: University College Dublin Press.

Wodiczko, K. (1999) Critical Vehicles: Writings, Projects, Interviews. Cambridge, MA: MIT Press.

Young, I. M. (1990) Justice and the Politics of Difference. Princeton, NJ: Princeton University Press.

Young, I. M. (2000) Inclusion and Democracy. Oxford: Oxford University Press. 